Arq. Bras. Med. Vet. Zootec., v.65, n.2, p.455-459, 2013

\title{
Manejo nutricional de cães e gatos domiciliados no estado do Espírito Santo - Brasil
}

\author{
[Feeding patterns of dogs and cats in Espírito Santo - Brazil] \\ K.P. Aptekmann ${ }^{1}$, A.F. Mendes-Junior ${ }^{2}$, W.G. Suhett ${ }^{2}$, U.C. Guberman ${ }^{2}$ \\ ${ }^{1}$ Centro de Ciências Agrárias - Universidade Federal do Espírito - Alegre, ES \\ ${ }^{2}$ Aluno de graduação - Centro de Ciências Agrárias - Universidade Federal do Espírito Santo - Alegre, ES
}

\begin{abstract}
RESUMO
Obtiveram-se informações sobre o manejo nutricional adotado para cães e gatos domiciliados, avaliou-se o grau de conhecimento dos proprietários e correlacionaram-se esses dados com fatores socioeconômicos dos entrevistados. Um questionário foi respondido por 496 proprietários de cães e/ou gatos. Verificou-se que os proprietários reconhecem que a alimentação está diretamente relacionada com a saúde animal e se preocupam com a qualidade do alimento fornecido. A ração seca é considerada a melhor opção para a alimentação de cães e gatos e é o tipo de alimento mais utilizado pelos proprietários. Os cães são alimentados preferencialmente duas vezes ao dia, e os gatos recebem alimento à vontade. Os proprietários buscam informações sobre a alimentação dos animais principalmente com veterinários ou estudantes de veterinária e lojas agropecuárias ou pet shops. Em geral, os proprietários de maior escolaridade têm preferência pela ração seca. O custo com a alimentação dos animais é considerado alto, especialmente para os proprietários que fornecem rações terapêuticas. Dessa forma, não são todos que podem arcar com esse custo. Observou-se que os proprietários que fornecem esse tipo de ração são os que apresentam maior poder aquisitivo. O tipo de alimento fornecido ao animal, ração ou comida caseira, não é influenciado pelo ambiente no qual o proprietário reside (rural ou urbano).
\end{abstract}

Palavras-chave: cão, gato, enquete, nutrição, questionário

\begin{abstract}
In this study, further information on nutritional management performed by dog and cat owners was obtained, the level of owners' knowledge about pet nutrition was assessed, and some aspects with socioeconomic background of respondents were correlated. A survey was conducted with 496 dog and cat owners. According to the results, owners recognize that nutrition is closely related to animal health and they care about the quality of food provided. Commercial dry foods are considered the best option for feeding dogs and cats and it is the type of food used by most owners. Dogs are fed preferably twice a day and cats ad libitum. Owners seek information on pet nutrition especially with veterinarians or veterinary students and agricultural shops or pet shops. In general, owners with higher education have a preference for dry foods. The cost with pet food is considered high, especially for owners who provide therapeutic diets. Few owners can afford this cost. We found that owners who provide this type of diet are those with higher purchasing power. The type of diet given to pets, commercial or homemade food, is not influenced by the environment in which the owner resides (rural or urban).
\end{abstract}

Keywords: dog, cat, survey, questionnaire, nutrition

\section{INTRODUÇÃO}

A nutrição é um dos principais fatores relacionados com a manutenção da saúde de cães e gatos, sendo que as práticas de alimentação

Recebido em 16 de agosto de 2011

Aceito em 11 de outubro de 2012

E-mail: kapreising@yahoo.com.br realizadas para animais domiciliados dependem exclusivamente das preferências e atitudes dos proprietários. Fatores como conhecimento sobre as necessidades nutricionais dos animais, nível socioeconômico dos proprietários, comunicação com veterinários e procura por materiais informativos podem influenciar nesse manejo. 
Estudos determinaram que a relação cãogato:habitante variou de 1:2,4 a 1:5,1 no cão, e de 1:16,4 a 1:30,6 no gato (Dias et al., 2004; Alves et al., 2005; Branco et al., 2007), dependendo da população estudada. Essas relações indicam um grande número de animais domiciliados no país. Contudo, faltam pesquisas que avaliem as condições de criação desses animais, ou que avaliem o conhecimento dos proprietários com relação às suas necessidades nutricionais.

Tal fato estimulou o desenvolvimento deste estudo, tendo como objetivo obter maiores informações sobre o manejo nutricional conferido aos animais, avaliar o grau de conhecimento dos proprietários sobre o assunto $\mathrm{e}$ correlacionar esses fatores com a renda familiar, a escolaridade e o ambiente onde vivem os entrevistados.

\section{MATERIAL MÉTODOS}

Realizou-se uma enquete com proprietários de cães e/ou gatos da região sul do estado do Espírito Santo por meio de entrevistas durante atendimento veterinário de rotina. Os proprietários foram esclarecidos sobre a pesquisa e responderam espontaneamente ao questionário, o qual foi elaborado segundo técnicas convencionais (Rea e Parker, 2002), contendo 20 perguntas objetivas de múltipla escolha e de fácil compreensão. Abordaram-se questões sobre as práticas de alimentação realizadas para os cães e gatos, o nível socioeconômico e o grau de conhecimento dos proprietários.

O entrevistador lia as perguntas e, quando necessário, especificava as alternativas para a resposta. As informações obtidas foram registradas no papel e em seguida codificadas e tabuladas em planilhas do Microsoft Excel. Realizou-se uma análise estatística de frequência com descrição dos resultados. As diferenças entre as frequências entre os proprietários de cães e gatos foram testadas pelo Teste Binomial para duas amostras independentes. Para as correlações entre as questões utilizou-se o coeficiente de correlação de Spearman. Os testes foram realizados com significância de 0,05.

O estudo foi aprovado pelo Comitê de Ética da Universidade Federal do Espírito Santo, sob o protocolo n.63/2011.

\section{RESULTADOS E DISCUSSÃO}

A utilização de questionários direcionados a proprietários de cães e gatos pode ser considerada a principal ferramenta utilizada na tentativa de se obter dados reais sobre as práticas de manejo realizadas em animais de companhia domiciliados. Foram completados 496 questionários, sendo que 424 deles (85\%) forneceram informações provenientes de proprietários de cães e 72 (15\%), de proprietários de gatos.

A população estudada foi composta por cães com menos de um ano de idade (22\%), entre um e sete anos (62\%) e mais de sete anos (13\%). Dentre os gatos, $35 \%$ tinham menos de um ano de idade, $56 \%$ entre um e sete anos e $4 \%$ mais de sete anos de idade. $\mathrm{O}$ restante dos respondentes $3 \%$ dos proprietários de cães e $5 \%$ dos proprietários de gatos - não soube informar a idade dos animais.

Ao serem questionados sobre a saúde de seus animais, responderam que $76 \%$ dos cães e $90 \%$ dos gatos foram considerados saudáveis, $21 \%$ dos cães e 4\% dos gatos foram julgados saudáveis, mas com problemas ocasionais, e 3\% dos cães e $6 \%$ dos gatos foram considerados doentes. Quanto maior a idade, maiores problemas de saúde foram relatados pelos proprietários ( $\mathrm{rs}=0,26 ; \mathrm{P}<0,01)$.

O principal alimento fornecido aos cães foi a ração comercial seca, de acordo com as respostas de $90 \%$ dos proprietários. Dezesseis por cento dos cães eram alimentados somente com alimento caseiro, sendo que $26 \%$ dos proprietários preparavam o alimento especialmente para o cão e $74 \%$ ofereciam alimentos preparados para o consumo familiar. Quatro por cento dos cães consumiam ração seca associada com o alimento caseiro. Apenas $2 \%$ eram alimentados com ração úmida e $1 \%$ com ração terapêutica.

Os proprietários de gatos afirmaram alimentarem seus animais com ração seca $(81 \%)$, alimento caseiro (11\%), ração úmida $(4 \%)$ e/ou ração terapêutica $(4 \%)$. Dentre os que ofereciam alimento caseiro, $8 \%$ forneciam alimentos preparados para o consumo familiar e o restante $(92 \%)$ oferecia alimentos preparados especialmente para os gatos. 
O fornecimento de rações comerciais secas para cães também foi reportado pela maioria de proprietários entrevistados em outros três grandes estudos (Laflamme et al., 2008; Michel et al., 2008; Remillard, 2008). A ampla utilização de rações comerciais nutricionalmente completas e balanceadas tem sido citada como um fator que aumenta expectativa e qualidade de vida em cães e gatos (Kraft, 1998). Segundo dados da Associação Nacional dos Fabricantes de Alimentos para Animais de Estimação (ANFAL-PET), o mercado de produtos para animais de estimação vem aumentando a cada ano e muitas são as opções de alimentos comerciais para cães e gatos. Porém, ainda existem proprietários que são refratários à utilização da ração e alimentam seus animais com comida caseira.

Contudo, está aumentando o interesse de veterinários e proprietários pelo uso de dietas não comerciais para seus animais, ditas como mais naturais ou orgânicas (Berschneider, 2002; Smart et al., 2007). Porém, os proprietários devem ser orientados por veterinários a prepararem alimentos especialmente destinados aos animais, na tentativa de evitar deficiências nutricionais e outras complicações decorrentes da alimentação desbalanceada (Kawaguchi et al., 1993; Streiff et al., 2002; Delay e Laing, 2006; Fornel-Thibaud et al., 2007).

Rahman e Yathiraj (2000) verificaram diminuição na incidência de diversos problemas de saúde em cães alimentados com ração em vez de alimento caseiro. Porém, no presente estudo, não se observou correlação significativa entre o estado de saúde de cães ou gatos com o oferecimento de ração ( $\mathrm{rs}=-0,013 ; \mathrm{P}=0,77$ ) ou alimento caseiro ( $\mathrm{rs}=-0,05 ; \mathrm{P}=0,2)$.

Maior proporção de cães era alimentada com ração seca em relação aos gatos $(\mathrm{P}=0,02)$. Não houve diferença significativa na porcentagem de fornecimento de alimento caseiro entre cães e gatos $(\mathrm{P}>0,05)$. Apesar de pouco utilizada, proprietários de gatos relataram fornecer ração terapêutica com maior frequência do que proprietários de cães $(\mathrm{P}=0,03)$.

As rações terapêuticas têm sido utilizadas para cães e gatos direcionadas para animais com diversas doenças (Freeman et al., 2006). Contudo, o presente estudo revelou que, apesar de $22 \%$ dos cães e gatos apresentarem-se doentes ou com problemas ocasionais, somente $1 \%$ dos cães e $4 \%$ dos gatos recebiam ração terapêutica, resultado semelhante ao encontrado por Laflamme et al. (2008) (1,7\% de cães e 3,6\% do gatos). Mesmo com a pequena porcentagem de utilização de ração terapêutica, houve correlação significativa entre o fornecimento desse tipo de alimento e animais considerados doentes pelos proprietários ( $\mathrm{rs}=0,1 ; \mathrm{P}=0,03)$.

Houve grande variação na frequência com que os alimentos eram oferecidos aos animais: uma vez ao dia ( $15 \%$ dos cães e $10 \%$ dos gatos), duas vezes ao dia (49\% dos cães e $33 \%$ dos gatos), três vezes ao dia ( $8 \%$ dos cães), mais de três vezes ao dia (1\% dos cães) e alimento à vontade (26\% dos cães e $51 \%$ dos gatos). Verificou-se que os gatos eram alimentados preferencialmente com alimento à vontade ( $\mathrm{P}<0,0001)$, assim como observado por Laflamme et al. (2008). Os proprietários de cães ofereciam o alimento preferencialmente duas vezes ao dia $(\mathrm{P}=0,01)$. De forma semelhante, Laflamme et al. (2008) verificaram que a alimentação fornecida aos cães duas vezes ao dia foi a mais comum, porém também observou uma alta porcentagem de cães alimentados uma vez a o dia.

Setenta e dois por cento dos proprietários de gatos e $67 \%$ dos proprietários de cães referiram oferecer outros alimentos aos seus animais além da ração ou alimento caseiro. Houve correlação entre $o$ fornecimento de ração seca e o oferecimento de petiscos, sendo que $70 \%$ dos proprietários que forneciam ração também forneciam petiscos aos animais ( $\mathrm{rs}=0,10$; $\mathrm{P}=0,02)$.

A ração comercial foi considerada o melhor alimento para o consumo de seus animais na opinião de $95 \%$ dos proprietários de cães e $92 \%$ dos proprietários de gatos. Oitenta e seis por cento dos proprietários de cães e $89 \%$ dos de gatos afirmaram que procuram saber se a ração oferecida é de boa qualidade. A oferta de alimento caseiro foi referida como sendo a melhor opção para 5\% dos proprietários de cães e $8 \%$ dos de gatos.

Segundo $97 \%$ dos proprietários de cães e $92 \%$ dos proprietários de gatos, a qualidade da alimentação é importante para a saúde animal. Os proprietários que consideraram a alimentação 
importante para a saúde dos animais eram principalmente os que forneciam ração seca ( $\mathrm{rs}=-0,23, \mathrm{P}=<0,01)$. Os proprietários foram questionados sobre a qualidade do alimento que ofereciam a seus animais e foi considerada excelente $(46,5 \%)$, de boa qualidade $(53 \%)$ e ruim $(0,5 \%)$ pelos proprietários de cães; excelente $(56 \%)$ ou de boa qualidade $(43 \%)$ e ruim $(1 \%)$ pelos proprietários de gatos. Noventa por cento dos proprietários de cães e $94 \%$ dos proprietários de gatos afirmaram acreditar que as necessidades de seus animais eram supridas pela alimentação oferecida.

Atualmente, a facilidade de acesso à informação é fator determinante para a escolha do tipo de alimento. Oitenta e um por cento dos proprietários de cães e $63 \%$ dos proprietários de gatos buscavam informações sobre o tipo de alimentação. Os meios mais utilizados por proprietários de cães foram: lojas agropecuárias ou pet shops $(41 \%)$, consulta a veterinários ou estudantes de veterinária (32\%), internet (30\%), revistas (16\%), amigos (4\%), TV ou rádio $(4 \%)$ e outros $(2 \%)$. Os proprietários de gatos referiram consultar veterinários ou estudantes de veterinária (61\%), lojas agropecuárias ou pet shops (56\%), internet (53\%), revistas (18\%) e amigos (4\%).

A consulta a veterinários foi a maior fonte de informações utilizada por proprietários de cães e gatos no estudo de Laflamme et al. (2008). Isso também foi observado neste estudo com proprietários de gatos, mas não com proprietários de cães, os quais buscavam informações principalmente em lojas agropecuárias e pet shops. De qualquer maneira, os veterinários devem estar preparados para orientar os proprietários de forma correta com relação ao manejo nutricional dos animais.

A maioria dos proprietários que forneciam ração $(64,3 \%)$ buscava informações sobre o tipo de alimento oferecido ao animal ( $\mathrm{rs}=-0,15 ; \mathrm{P}=0,01)$. Ao contrário dos que ofereciam alimento caseiro, em que a maioria $(60,4 \%)$ não buscava informações ( $\mathrm{rs}=0,23 ; \mathrm{P}<0,0001)$.

Quanto ao custo com a alimentação, $14 \%$ e $15 \%$ dos proprietários de cães e gatos, respectivamente, consideram um custo alto, $47 \%$ e $24 \%$, um custo médio, $32 \%$ e $60 \%$, um custo baixo. Sete por cento dos proprietários de cães e $1 \%$ dos proprietários de gatos não souberam informar sobre seus gastos com a alimentação dos animais. Os proprietários de gatos consideram o custo mais baixo do que os proprietários de cães $(\mathrm{P}<0,0001)$. Proprietários que forneciam ração consideraram médio o custo com alimentação (rs=0,14, $\mathrm{P}=0,002)$ e os que forneciam ração terapêutica consideraram $\mathrm{O}$ custo alto (rs=-0,11, $\mathrm{P}=0,009$ ).

Foram realizadas perguntas sobre a escolaridade, renda familiar e local de moradia dos entrevistados na tentativa de correlacionar essas informações com as demais obtidas no questionário. A maioria dos entrevistados (71\%) cursou entre o ensino médio e superior, $22 \%$ entre a quinta e a oitava série do ensino fundamental e $7 \%$ eram analfabetos ou cursaram até a quarta série do ensino fundamental. De acordo com os dados obtidos, quanto maior a escolaridade maior a preferência pela ração seca ( $\mathrm{rs}=0,21 ; \mathrm{P}<0,01)$.

Quanto à renda média da família (em salários mínimos), 28\% recebiam acima de $4 ; 36 \%$, de 2 a $4 ; 22 \%$, de 1 a 2 ; e $2 \%$, abaixo de um salário mínimo. Doze por cento se negou a responder ou não soube informar. A maior parte dos entrevistados que fornecia alimento caseiro aos cães e gatos apresentava renda média familiar de 2 a 4 salários mínimos ( $\mathrm{rs}=-0,12 ; \mathrm{P}=0,004)$; os que forneciam ração terapêutica apresentavam renda média superior a 4 salários mínimos ( $\mathrm{rs}=0,096 ; \mathrm{P}=0,033)$.

Dentre os entrevistados, 91\% viviam na área urbana e 9\%, na área rural. Não houve correlação entre o fornecimento de ração ( $r s=-0,01 ; \mathrm{P}=0,8)$ ou alimento caseiro ( $\mathrm{rs}=-0,04 ; \mathrm{P}=0,30)$ com o fato de o proprietário viver em ambiente rural ou urbano.

\section{CONCLUSÕES}

As informações obtidas neste questionário podem auxiliar médicos veterinários a identificar as práticas de manejo mais comuns realizadas em cães e gatos domiciliados e podem guiar suas orientações aos proprietários com relação à nutrição animal. 


\section{AGRADECIMENTOS}

Os autores agradecem a colaboração de todos os proprietários que responderam voluntariamente aos questionários.

\section{REFERÊNCIAS}

ALVES, M.C.G.P.; MATOS, M.R.; REICHMANN M.L. et al. Dimensionamento da população de cães e gatos do interior do Estado de São Paulo. Rev. Saúde Publ., v.39, p.891-897, 2005.

BERSCHNEIDER, H.M. Alternative diets. Clin. Tech. Small Anim. Pract., v.17, p.1-5, 2002.

BRANCO, I.D.; JAVOROUSKI, E.B.; RIBEIRO, K.G. et al. Estimativa da população de cães e gatos domiciliados em área de proteção ambiental de Piraquara, região metropolitana de Curitiba, Brasil. In: CONGRESSO BRASILEIRO DE MEDICINA VETERINÁRIA， 35., 2008， Gramado. Anais... Gramado: (s.n) 2008. (Resumo).

DELAY, J.; LAING, J. Nutritional osteodystrophy in puppies fed a BARF diet. Anim. Health Newsletter, v.6, p.23, 2002.

DIAS, R.A.; GARCIA, R.C.; SILVA, D.F. et al. Estimativa e populações canina e felina em zona urbana do estado de São Paulo. Rev.Saúde Públ., v.38, p.565-570, 2004.

FORNEL-THIBAUD, P.; BLANCHARD, G.; ESCOFFIER-CHATEAU, L. et al. Unusual case of osteopenia associated with nutritional calcium and vitamin $\mathrm{D}$ deficiency in an adult dog. J. Am. Anim. Hosp. Assoc., v.43, p.52-60, 2007.

FREEMAN, L.M.; ABOOD, S.K.; FASCETTI, A.J. et al. Disease prevalence among dogs and cats in the United States and Austrália and proportions of dogs and cats that receive therapeutic diets or dietary supplements. J. Am. Vet. Med. Assoc., v.229, p.531534, 2006.
KAWAGUCHI, K.; BRAGA, I.S.; TAKAHASHI, A. et al. Nutritional secondary hyperparathyroidism occurring in a strain of German Shepherd puppies. Jpn. J. Vet. Res., v.41, p.89-96, 1993.

KRAFT, W. Geriatrics in canine and feline internal medicine. Eur. J. Med. Res., v.3, p.31-41, 1998.

LAFLAMME, D.P.; ABOOD, S.K.; FASCETTI, A.J. et al. Pet feeding practices of dog and cat owners in the United States and Australia J. Am. Vet. Med. Assoc., v.232, p.687-694, 2008.

MICHEL, K.E.; WILlOUGHBY, K.N.; ABOOD, S.K. et al. Attitudes of pet owners toward pet foods and feeding management of cats and dogs. J. Am. Vet. Med. Assoc., v.233, p.1699-1703, 2008.

RAHMAN, S.A.; YATHIRA, J.S. Commercial versus traditional food in canine health (abstr). Compend. Contin. Educ. Pract. Vet., v.97, p.97, 2000.

REA, L.M.; PARKER, R.A. Metodologia de pesquisa, do planejamento à execução. São Paulo: Pioneira Thomson Learning, 2002. 262p.

REMILLARD, R.L. Homemade diets: attributes, pitfalls, and a call for action. Top. Comp. Animal Med., v.23, p.137-142, 2008.

SMART, M.E.; MILLS, J.A.; HAGGART, C. Pet Food Industry and Nutrition: A Necessary Review For Veterinarians, 2007. Disponível em: <http://www.vin.com/doc/?id=2994123>. Acessado em 08 Ago. 2012.

STREIFF, E.L.; ZWISCHENBERGER, B.; BUTTERWICK, R.F. et al. A comparison of the nutritional adequacy of home-prepared and commercial diets for dogs. J. Nutr., v.132, p.1698S1700S, 2002. 